\title{
Succession in the aquatic Sarracenia purpurea community: deterministic or driven by contingency?
}

\author{
Sarah M. Gray
}

Received: 12 April 2012/Accepted: 1 October 2012/Published online: 19 October 2012

(C) Springer Science+Business Media Dordrecht 2012

\begin{abstract}
The development of a community through time, or succession, is generally described as the orderly replacement of species until a deterministic, stable endpoint is reached. However, stochastic factors, coupled with intrinsic biotic factors, such as herbivory or predation, can cause communities within the same habitat to become highly dissimilar in composition. Much research on the succession of terrestrial systems has been conducted, but factors influencing the succession of a terrestrial system may not apply to aquatic systems. To determine whether succession in an aquatic system is deterministic or dominated by contingency of stochastic factors, and the role that higher trophic level interactions and resources have in shaping successional patterns,
\end{abstract}

Handling Editor: Liesbeth Bakker

Electronic supplementary material The online version of this article (doi:10.1007/s10452-012-9417-9) contains supplementary material, which is available to authorized users.

\section{S. M. Gray}

Department of Ecology and Evolution, Stony Brook University, 650 Life Sciences Building, Stony Brook, NY 11794-5245, USA

Present Address:

S. M. Gray $(\square)$

Unit of Ecology and Evolution, Department of Biology, University of Fribourg, Ch. Du Musée 10, 1700 Fribourg, Switzerland

e-mail: sarahmarie.gray@unifr.ch
I followed community development and dynamics of the intermediate and bottom trophic level (protozoans and bacteria) in the model Sarracenia purpurea pitcher plant system throughout an entire growing season. By comparing these dynamics across pitcher plant leaves within the same bog, I was able to determine whether there is a predictable pattern for community assembly in this aquatic community. The results from this study suggest that rather than a sequential replacement of early colonizers with more competitive species through time, competitively superior species establish in newly formed communities simultaneously with less competitive species, which coexist throughout the growing season. Community assembly in this system can also be altered by stochastic events. Resources and predators had a variable effect on the patterns of community change observed during succession. Patterns of community assembly were also dependent on the trophic level examined but, for the bottom trophic level, not on the sampling method used.

Keywords Food web - Inquiline community · Operational Taxonomic Unit (OTU) ·

Sarracenia purpurea $\cdot$ Succession $\cdot 16 \mathrm{~S}$ rRNA cloning

\section{Introduction}

Community change through time, or succession, has been of great ecological interest over the last century. 
To date, notions of the process of succession within a community have built on those set forth by Clements (1916, 1936) and Gleason (1917, 1926), and decades of research, including the development of alternative models (Connell and Slatyer 1977), have resulted from these early debates as researchers search for predictable patterns of succession in a community.

If succession occurs according to Clements (1916, 1936), communities should be driven to a deterministic endpoint, in which the first species that arrives in a habitat modifies the environment, facilitating the success of later arriving competitively superior species. Ultimately, these early settlers will be replaced in the community until the community is dominated by species that can successfully persist (climax community), driving communities in the same habitat type to converge in similarity (Clements 1916, 1936; Odum 1969). Yet, according to Gleason $(1917,1927)$, community succession is instead a stochastic process driven by contingency, allowing communities to diverge throughout succession (Gleason 1917, 1927; Berlow 1997). Alternatively, theoretical models (Connell and Slatyer 1977) have suggested that early succession species might either have little, none, or a negative effect on the establishment of new species, which will reduce the predictability of species replacement through time within a community.

The research that has resulted from these early debates has traditionally focused on terrestrial systems, and, in particular, the successional patterns of plants (Connell and Slatyer 1977). However, the factors important for succession in terrestrial systems might not be the same as those in aquatic systems. For example, Huchinson's 'Paradox of the Plankton' (1961) suggested that if species were being competitively excluded through community development, one would not see such a high diversity of plankton as is observed in aquatic habitats with a limited range of resources. Although the main driver of succession in terrestrial systems is thought to be competition, other important interactions, such as herbivory or predation, are also known to play central roles in shaping community dynamics and could be important during succession. Top predators, for example, are known to greatly affect diversity, abundances and the ability of species to coexist (e.g., Paine 1966), yet how these interactions affect community succession has rarely been explored in aquatic systems (e.g., Chase et al. 2009).
To determine whether succession in an aquatic system is deterministic or dominated by contingency, and the role of higher trophic level interactions and resources in shaping successional patterns, I followed the community dynamics in the model Sarracenia purpurea pitcher plant system throughout an entire growing season. By doing this, changes in abundances and species richness were determined through time. By comparing these dynamics across pitcher plant leaves within the same bog, I was also able to determine whether there is a predictable pattern for community assembly in this aquatic community.

Each leaf of a $S$. purpurea plant represents a habitat island, in which colonization of the aquatic community begins with the opening of a new leaf as a new habitat. No species are present in the community before the leaf opens (Peterson et al. 2008) and each habitat island within a bog has access to the same regional pool. The species that colonize each habitat island are predominately microorganisms with short generation times and insect larvae, making this system ideal for following successional patterns through hundreds to thousands of generations and across multiple habitat islands (e.g., Koopman et al. 2010 for the co-gener S. alata, Miller and terHorst 2012). Larger scale systems contain longer-lived organisms, limiting the long-term datasets needed to determine whether a community has a successional endpoint.

Every month for 6 months in 2007, I assessed the abundance and richness of the entire $S$. purpurea community within pitchers to assess: (1) whether succession within this aquatic community is driven by deterministic or stochastic processes, (2) whether resource availability and higher trophic level interactions affected these results and (3) the predictability of the observed successional patterns across multiple communities within this system. In 2008, I took advantage of an opportunity to resample the beginning and end time points of the $S$. purpurea aquatic community (June and November). For this sampling, $16 \mathrm{~S}$ rRNA cloning was incorporated to determine whether the successional pattern found when considering a larger diversity of bacteria was the same as when only culturable bacteria were studied, and how different sampling methods for the bacteria may affect the conclusions drawn about the successional trajectory of a system. 
Study system

The pitcher plant $S$. purpurea is a carnivorous plant found in nutrient poor habitats throughout the eastern coast and mid-west of the United States and in most of Canada. Each plant forms a rosette of leaves, each with an inquiline aquatic community. Leaf production begins at the beginning of the season and continues until the onset of fall and winter (Fish and Hall 1978). Since the plant does not receive an adequate amount of essential nutrients (primarily nitrogen) from the soil, it has evolved pitcher-shaped leaves that fill with rainwater and attract and passively drown insects. These insects are then decomposed by bacteria, releasing the nutrients for the plant to use. The bacteria continuously have predation pressure from protozoans and rotifers, which form the intermediate trophic level in this community. The larval stage of the endemic mosquito species Wyeomyia smithii, which inhabits the top trophic level, consumes the protozoans and rotifers, alleviating predation pressure on the bottom trophic level (Kneitel and Miller 2002). An endemic midge, Metriocnemus knabi, breaks insects into smaller pieces, facilitating decomposition and release of nutrients for the plant (Heard 1994). Fleshfly larvae, Blaesoxipha fletcheri, are rare members of the pitcher plant community and are thought to consume first-instar mosquito larvae and insects as they fall into the pitcher (Gotelli and Ellison 2006). The morphotypes of the culturable bacteria and protozoans, rotifer and dipteran larvae species in this community are thought to be the same throughout the entire geographic range of the plant (Buckley et al. 2010). However, when 16 S rRNA cloning techniques were used, the dominant genera of bacteria were found to be different or occur in different proportions among pitchers within a bog and among bogs (New York and Florida field sites) (Gray 2011).

\section{Methods}

Field site and aquatic community sampling

The study area was a sphagnum moss bog in the Pine Barrens region near Riverhead, New York, USA (Cranberry Bog Preserve, $40^{\circ} \mathrm{N}, 72^{\circ} \mathrm{W}$ ). The common vegetation found in or surrounding the bog includes pitch pine (Pinus rigida), Sphagnum sp. moss, sundews (Drosera sp.) and the giant reed Phragmites australis. This bog includes several hundred northern pitcher plants, S. purpurea.

I sampled the aquatic community inside the leaves of S. purpurea at this field site in two different years. In 2007, the community in 20 marked leaves was followed at monthly intervals from June (beginning of the growing season) until either the leaf died or to November (end of the growing season, before the first freeze). For each sampling date, the water volume and clarity, accumulated insect input, abundance and richness of culturable bacteria and protozoan species, rotifer (Habrotrocha rosa) abundance, the abundance and instar level of mosquito larvae (W. smithii) and the abundance of the midge ( $M$. knabi) and flesh-fly larvae (Sarraceniopus gibsoni) were assessed. In 2008, I sampled 6 leaves in June and 5 additional leaves in November. For both sampling dates in 2008, the same data were recorded as in 2007 , as well as the diversity and abundance of both the culturable and unculturable bacteria. The diversity and relative abundance of the bacterial community including unculturable species were determined with $16 \mathrm{~S}$ rRNA clone library techniques.

In both 2007 and 2008, I randomly marked unopened leaves (one per pitcher plant) throughout the bog at the beginning of Sarracenia's growing season. Two weeks later, those designated leaves that had opened into their characteristic pitcher shape were the leaves used for sampling. In 2008, because $16 \mathrm{~S}$ rRNA cloning requires using the contents of the entire community without replacement, the communities that were sampled in June were not the same communities sampled in November. However, the leaves sampled in November were chosen from the same set of leaves marked as unopened at the beginning of the season. Due to herbivory and weather damage, only 5 of the unopened, marked leaves from the beginning of the season were healthy enough for sampling in November. Different plants were sampled in 2007 and 2008.

The water collected from pitchers in 2007 was first gently mixed with a sterile pipette, and then transferred into a sterile 50- $\mathrm{ml}$ macrocentrifuge tube. Using the same methods as in Miller and terHorst (2012), the water volume and clarity, the number and instar level of the mosquito larvae, the number of newly captured ants and other insects and the abundances of midges and flesh-fly larvae were recorded. I transferred a 
$0.2 \mathrm{ml}$ aliquot of the aquatic community to a sterile microcentrifuge tube, which was returned to the laboratory for further analysis. The remainder of the water and community was returned to the pitcher plant leaf and left until the next sampling date. From the water returned to the lab, a $0.1 \mathrm{ml}$ aliquot was used to determine the densities and richness of protozoan species and rotifers using a compound microscope according to standard methods (Kneitel and Miller 2002; Gray et al. 2006; Miller and terHorst 2012). A second aliquot of $0.5 \mathrm{ml}$ was used to plate culturable bacteria for each sample in $10^{-3}$ and $10^{-5}$ serial dilutions on LB agar. These plates were incubated at $27^{\circ} \mathrm{C}$ for 2 days, and then, the abundances and richness of the colony-forming units (CFUs) were determined from the number of different CFU morphologies (according to texture, color and shape) that grew on the agar plate (e.g., Kneitel and Miller 2002; Gray et al. 2006; Miller and terHorst 2012).

In 2008, the water in each selected leaf was gently mixed with a sterile pipette and collected into individually labeled, sterile 50-ml centrifuge tubes. The entire content of each sample was then transferred on ice back to the laboratory for further analysis of the aquatic community (using the same methods as in 2007). In addition, I constructed $16 \mathrm{~S}$ rRNA clone libraries to assess the entire community of bacteria.

Environmental clone library construction

Directly after processing samples at the beginning and end of the season in 2008, a $1 \mathrm{ml}$ aliquot of water from each sample was filtered onto a $0.22-\mu \mathrm{M}$ Isopore membrane filter (Millipore, Billerica, Massachusetts) to collect all bacteria (both culturable and unculturable bacterial cells). After filtration, DNA was extracted from the microbial community found on each filter with the Ultra Clean Soil DNA kit according to manufacturer's instructions (Mo Bio Laboratories, Solana Beach, California), with the exception of step 1 of the protocol, where instead of using a soil sample, I placed the filter containing the bacteria in the bead solution tubes with $200 \mu \mathrm{l}$ of sterile water. Extracted DNA was stored at $-20^{\circ} \mathrm{C}$ until used for PCR amplification.

During PCR amplification, I used the Bacteria domain-specific SSU rRNA gene primers $27 \mathrm{~F}$ (5'-AGA GTT TGA TCM TGG CTC AG -3') (Johnson 1994) and 1392R (5'-ACG GGC GGT GTG TAC-3')
(Wilson et al. 1990). The PCR conditions were $95^{\circ} \mathrm{C}$ for $5 \mathrm{~min}, 94{ }^{\circ} \mathrm{C}$ for $1 \mathrm{~min}, 52{ }^{\circ} \mathrm{C}$ for $30 \mathrm{~s}, 72{ }^{\circ} \mathrm{C}$ for $3 \mathrm{~min}$, steps 2-4 repeated 30 times, and a final step of $72{ }^{\circ} \mathrm{C}$ for $10 \mathrm{~min}$. The PCR products were purified with the Qiagen PCR Purification Kit (QIAGEN, Valencia, CA, USA), and the purified product was ligated into the TOPO TA cloning vector pCR 2.1 according to manufacturer's instructions (Invitrogen, Carlsbad, CA, USA). Ligation reactions were sent to The Genome Center at Washington University (St. Louis, Missouri) where they were transformed and a total of 96 clones were sequenced for each library. Clones were sequenced using the primer $907 \mathrm{R}$ (5'-CCG TCA ATT CMT TTG AGT TT 3').

Using Sequencher v4.8 (Gene Codes Corp., Ann Arbor, MI), vector sequences flanking the SSU rRNA gene inserts were removed, sequences were trimmed and sequences below $90 \%$ quality threshold and $<300$ bp were deleted. The remaining sequences were then assembled and sent to Greengenes (DeSantis et al. 2006, http://greengenes.lbl.gov) to be aligned. Clone libraries were then developed based on of these aligned sequences, with an OTU defined as having $97 \%$ sequence similarity.

Community composition and diversity indices

To calculate Pielou's evenness and Shannon Diversity indices for the communities sampled in 2007 and 2008, I used the multivariate statistical program Primer 6.1 (PRIMER 6, Version 6.1.6, Primer E-Ltd. 2006). Primer 6.1 was also used for statistical analyses to test for similarity in the culturable bacterial community and the assemblage of protozoans among sampling periods in 2007, and for the 16S rRNA bacterial data obtained from the June and November samples of 2008. Community similarity was tested using just presence/absence data, as well as abundances of individual OTUs and culturable bacteria morphotypes within samples. When OTU data were used, each clone library was standardized to 49 randomly selected sequences. For tests of community similarity based on abundance data, data were normalized with a squareroot transformation. Bray-Curtis distances were calculated, which use values from 0 (most similar) to 1 (least similar) to determine similarity between samples (Bray and Curtis 1957). To graphically visualize the differences between bacterial communities, a non-metric multi-dimensional scaling (MDS) 
plot was used. Communities that are more similar are spatially close on a MDS plot; those that are less similar are more spatially separated. Analysis of similarity (ANOSIM) was used to calculate a global R, which was used to determine the overall similarity between communities, and ranges from 1 (extreme dissimilarity) to 0 (complete overlap in community composition).

To determine whether community succession was driven by deterministic processes, the competitive ability of the most common bacteria and protozoans found in this system (Buckley et al. 2010) was determined by conducting pairwise competition experiments. In these experiments, the most common protozoans and bacteria in the $S$. purpurea system were isolated and changes in abundance were recorded when the isolates were grown alone and when they were grown in pairwise combinations with other isolates from the same trophic level (Kneitel 2002; Gray 2011).

\section{Results}

Within month comparison of culturable bacteria communities: 2007

Within each month, communities were divergent in their similarity for both abundances (Fig. 1a) and presence/absence (Figure S1a) of individual morphotypes. When comparing communities that contained new ant input to communities with no ant input, low ANOSIM values resulted, suggesting that the presence of ants did not explain the differences in culturable bacteria composition among communities within that month (Clarke and Gorley 2006; June abundances: ANOSIM $=0.078, p$ value $=0.15$; June presence/ absence: ANOSIM $=0.115, p$ value $=0.08$; July abundances ANOSIM $=0.027, p$ value $=0.289$; July presence/absence $\mathrm{ANOSIM}=0.042, p$ value $=0.675$; August, no ant input into any community, comparison could not be made; September abundance ANO$\mathrm{SIM}=0.22, p$ value $=0.152$; September presence/ absence ANOSIM $=0.061, p$ value $=0.286$; October and November, no ant input into the community, comparisons could not be made). However, in all cases, the $p$ values were not significant, suggesting that the sample size for the number of communities with no ants versus the number of communities with ants was not large enough for a full interpretation of the pattern (Clarke and Gorley 2006).

Within month comparison of protozoan communities

The variation in the community composition for protozoans based on abundances of individual species and presence/absence of species among communities was very similar to the results found for culturable bacteria (Fig. 1b, Figure S1b). During August (mid season), communities containing mosquitoes were significantly different in composition than those that did not contain mosquitoes (abundance ANO$\mathrm{SIM}=0.38, p$ value 0.003 ; presence/absence ANO$\mathrm{SIM}=0.306, \quad p \quad$ value $=0.008) . \quad$ MDS plots representing other months showed a similar separation between communities containing mosquitoes and communities not containing mosquitoes, but the ANOSIM values were low and the $p$ values were non-significant (sample size too small; Clarke and Gorley 2006) (June abundances: $\operatorname{ANOSIM}=0.00$, $p \quad$ value $=0.823$; June presence/absence: ANO$\mathrm{SIM}=0.00, \quad p$ value $=0.741 ;$ July abundances ANOSIM $=0.069, p$ value $=0.20 ;$ July presence/ absence $\mathrm{ANOSIM}=0.052, p$ value $=0.233$; September abundance ANOSIM $=0.042, p$ value $=$ 0.324; September presence/absence ANOSIM $=0.00$, $p$ value $=0.569 ;$ October abundance $\mathrm{ANOSIM}=$ $0.064, p$ value $=0.207$; October presence/absence ANOSIM $=0.155, p$ value $=0.089$; November abundance $\mathrm{ANOSIM}=0.012, p$ value $=0.397$; November presence/absence $\mathrm{ANOSIM}=0.00, p$ value $=$ 0.923). This result suggests that the top predator may be an explanatory factor for the within month variation in protozoan species composition.

Similarity in divergence and convergence patterns across months for culturable bacteria and protozoans

I then compared how similar bacterial communities were in abundance and morphotype identity among the months sampled. I found that the composition of culturable bacterial communities is dependent on the month sampled, with communities more similar to each other within a month than between months (Fig. 2a; ANOSIM for abundance $=0.461, p$ value $=0.001$; Figure S2a ANOSIM for presence/absence $=0.387$, 
(a) Abundance of Individual Culturable Bacteria

Ants in Community

No Ants in Community

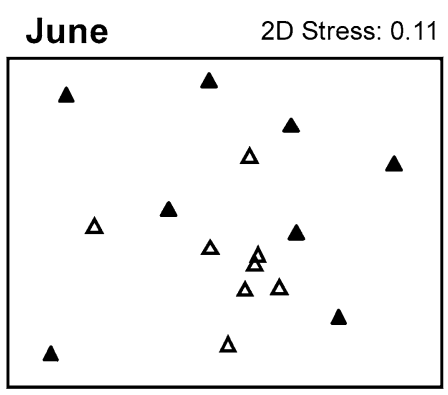

Communities with ants $=8 / 16$

September

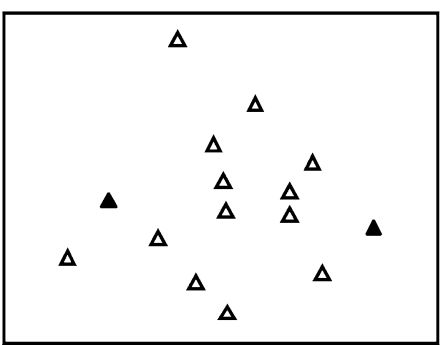

Communities with ants $=2 / 16$

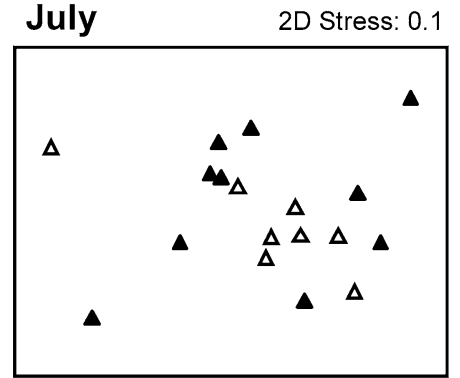

Communities with ants $=10 / 18$

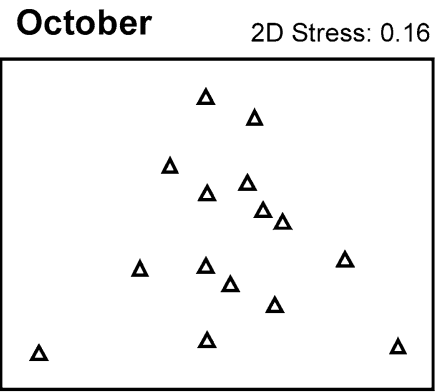

Communities with ants $=0 / 15$
August $\quad$ 2D Stress: 0.17

$\Delta \quad \Delta$

${ }_{\Delta}^{\Delta}{ }_{\Delta}^{\Delta}{ }^{\Delta} \Delta \Delta$

$\Delta$

${ }_{\Delta{ }_{\Delta}^{\Delta}}^{\Delta} \quad \Delta_{\Delta}^{\Delta}$

$\Delta$

Communities with ants $=0 / 18$

November 2D Stress: 0.09

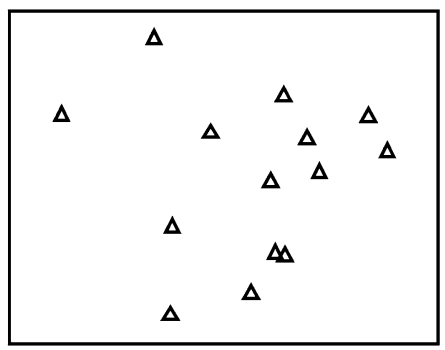

Communities with ants $=0 / 14$

(b) Abundance of Individual Protozoan Species

$\triangle$ Mosquitoes in Community $\triangle$ No Mosquitoes in Community

June

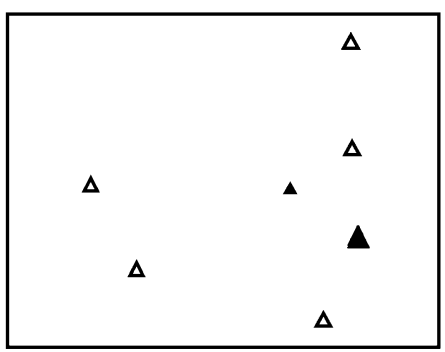

Communities with mosquitoes $=5 / 16$

September 2D Stress: 0.16

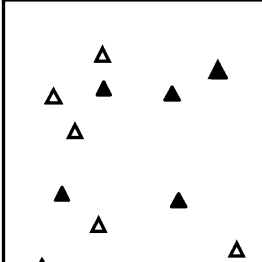

$\Delta \quad \Delta$

Communities with mosquitoes $=6 / 16$

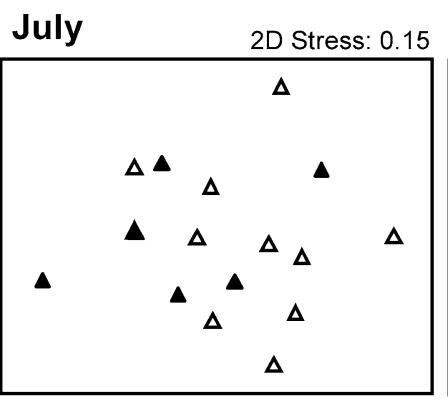

Communities with mosquitoes $=7 / 18$
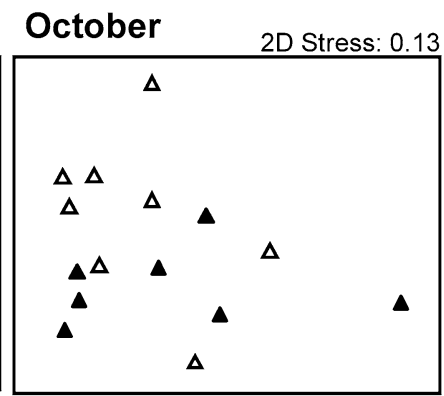

Communities with mosquitoes $=7 / 15$
August

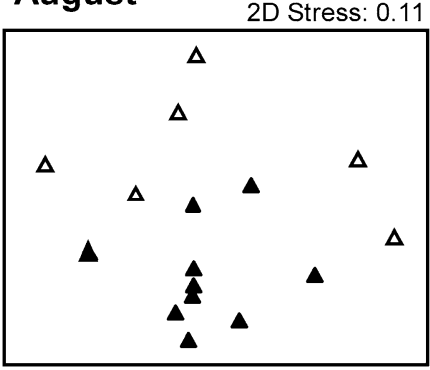

Communities with mosquitoes $=11 / 18$

November 2D Stress: 0.13

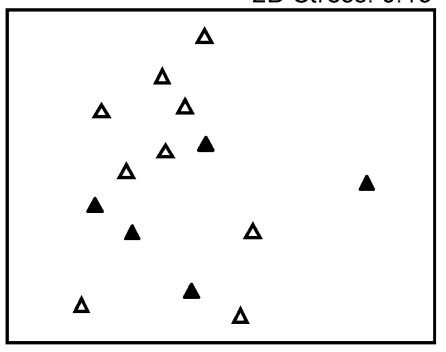

Communities with mosquitoes $=5 / 14$ 
4 Fig. 1 Multi-dimensional scaling (MDS) plots illustrating community similarity in a abundances of individual morphotypes of culturable bacteria (bottom trophic level), and b abundances of individual protozoan species (intermediate trophic level) found within 20 pitcher plant leaves (1 leaf per plant) sampled monthly throughout one growing season. Data used for MDS plots and ANOSIMs were square-root-transformed Bray-Curtis similarities. 2-D stress indicates how well multi-dimensional groupings are represented in a two-dimensional graph. In general, a stress $<0.2$ is considered an adequate representation. To visually show the importance of top predator and resource control on successional patterns, open triangles indicate communities with no ants (in a) or no mosquito larvae (in b) during the time of sampling. Closed triangles indicate those communities where ants (in a) or mosquito larvae (in b) were found in the water at the time of sampling. Communities that are highly similar to each other have symbols that overlay on top of each other, making some symbols appear to be missing or larger than others. Ant capture rate dramatically decreased to zero by August, while the presence of mosquito larvae in the communities was greatest in August

$p$ value $=0.001)$. Unlike culturable bacteria community composition, when protozoan communities were compared across months, there was little variation in protozoan composition between the months (Fig. 2b, abundance ANOSIM global $R=0.08, p$ value $=$ 0.003 ; Figure $\mathrm{S} 2 \mathrm{~b}$, presence/absence ANOSIM global $R=0.133, p$ value $=0.001$ )

Effect of top predator and resource control on the similarity in composition among months

When all sampled communities from all months were compared together, irrespective of month, those communities containing ants were more similar to each other in both abundance and morphotype identity than those communities that had no ant input throughout the season (abundance ANOSIM $=0.309, p$ value $=0.001$; presence/absence ANOSIM $=0.193, p$ value $=0.001$ ) Yet, for protozoan composition, the presence of mosquito larvae had no effect on altering community composition. When all months are compared together, communities containing mosquito larvae were similar in composition to those communities that never contained mosquito larvae, yet the $p$ value was nonsignificant (abundance ANOSIM $=0.022, p$ value $=$ 0.904 ; presence/absence ANOSIM $=0.012, p$ value $=$ 0.754). Although the top predator explains the variation in protozoan composition within months, it does not explain the differences in composition across months.

Species richness and abundance dynamics throughout succession

Figures 3 and 4 show the patterns of community assembly for the most common culturable bacteria and protozoans (those isolated and used in pairwise competition experiments), respectively. For culturable bacteria, every morphotype except the two least competitive morphotypes (pink and purple morphotype (Gray 2011) was found in these communities throughout the growing season, although their abundances changed through time (Fig. 3). Overall, the density of culturable bacteria decreased throughout the growing season, but species richness remained relatively constant (Table 1$)$. (a) Culturable Bacteria Abundances

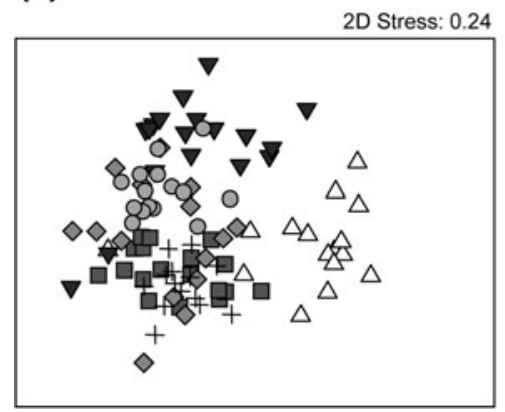

(b) Protozoan Abundances

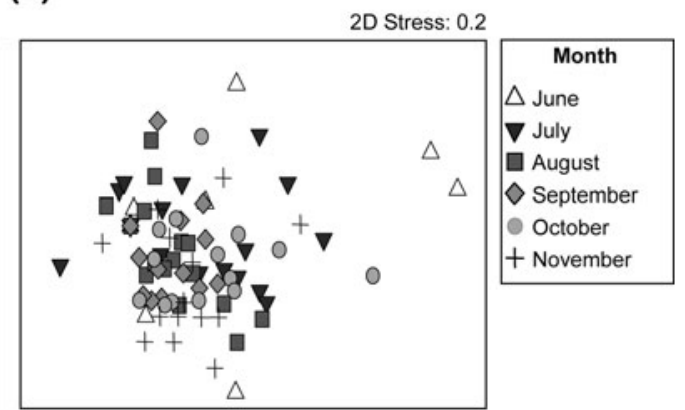

Fig. 2 Multi-dimensional scaling (MDS) plots illustrating community similarity between all months sampled for the $\mathbf{a}$ abundances of individual culturable bacteria and $\mathbf{b}$ protozoan species found within $\sim 20$ pitcher plant leaves. Data used for MDS plots and ANOSIMs were square-root-transformed BrayCurtis similarities. 2-D stress on MDS plots indicates how well multi-dimensional groupings are represented in a two-dimensional graph. In general, a stress $<0.2$ is considered an adequate representation. The MDS plots and ANOSIM results (ANOSIM global $\mathrm{R}$ for $\mathbf{a} 0.461, p$ value $=0.001$; for $\mathbf{b} 0.08$, $p$ value $=0.002$ ) show how similar community patterns are (if they converge or diverge) among months 
Competitive Ability Increases
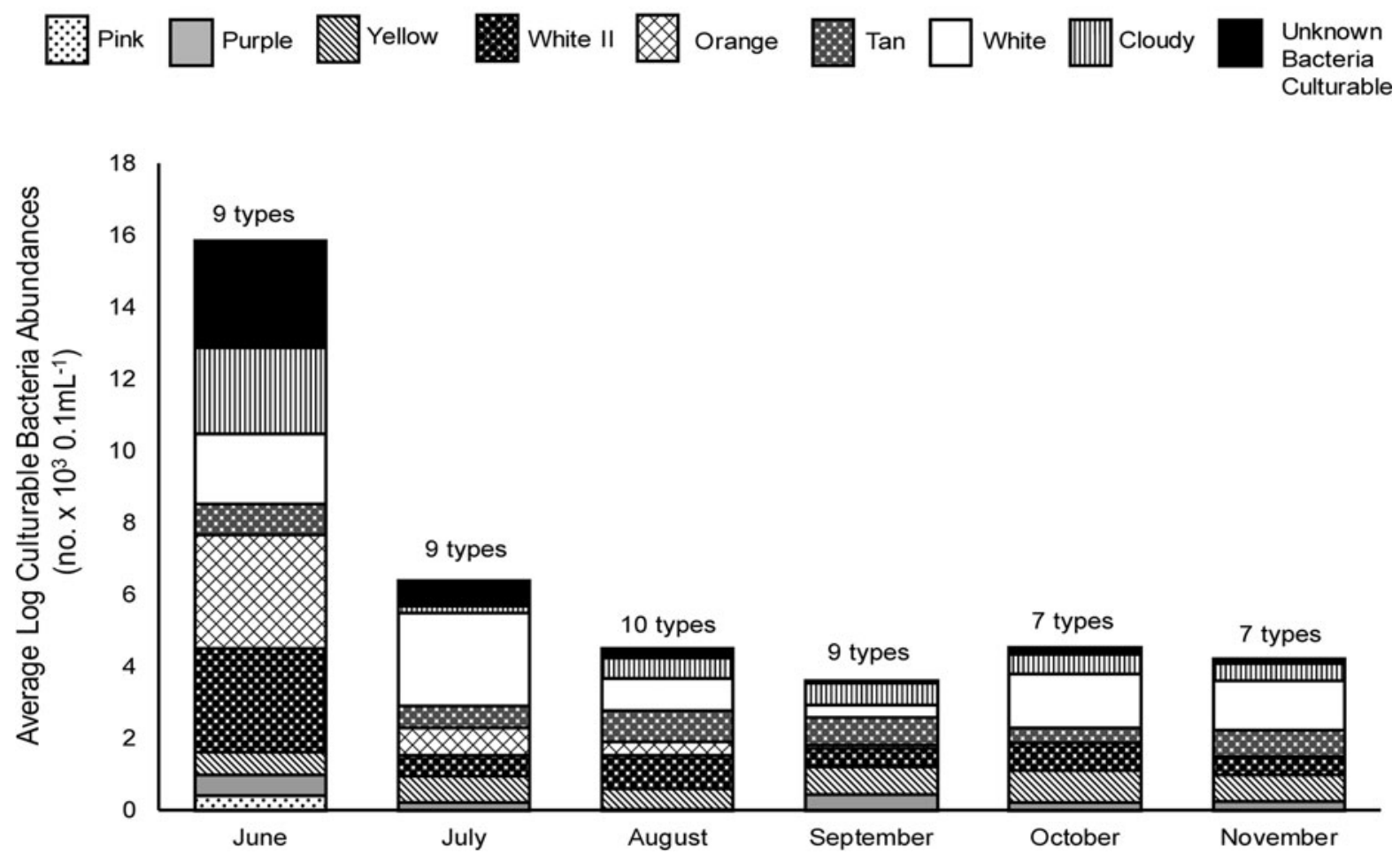

Fig. 3 Abundances and species richness of culturable bacteria averaged across 20 pitcher plant communities sampled monthly from June to November in 2007. Each bar on the graph represents the average log bacteria abundance (per $0.1 \mathrm{ml}$ ) per month. The abundance and richness were obtained by counting bacteria on agar plates. The culturable bacteria morphotypes highlighted in patterns and white and grey are ordered according to competitive ability with 'Pink' as the least competitive and 'Cloudy' as the most competitive (Gray 2011). The bacteria represented in black at the top of each bar are unknown morphotypes with undetermined competitive ability
The protozoans showed both similar and different dynamics as the bacteria. The least competitive species was present in communities throughout the entire growing season, and all common species were found in almost every month of the growing season, independent of their competitive ability (Fig. 4). In every month throughout succession, the majority of the sampled pitchers (except June) contained both flagellates and ciliates simultaneously within a pitcher (Fig. 4). This dynamic occurred even though the ciliate protozoans are larger in size and are known to be competitively dominant to flagellates in this system (Kneitel 2002). However, by the end of the season, pitcher plant communities accumulated a higher diversity of ciliate protozoans than flagellate protozoans, yet, the least competitive flagellate species was also found in high abundance at the end of the season
(Fig. 4). Protozoan densities and species richness had dynamics that were opposite to those found for bacteria. While culturable bacteria densities decreased and species richness remained constant through time, both total protozoan densities and richness increased as succession progressed (Table 1).

Comparison of abundance and presence/absence dynamics of 16S rRNA bacterial clones (2008) to culturable bacteria successional patterns (2007)

Figure 5a, b and Figure S3a, b illustrate MDS plots to help to understand whether the pattern found for bacterial community succession in 2007 could be replicated with different methods (culturing techniques and 16S rRNA OTUs) and across years. By using the 16S rRNA cloning method in 2008, I was able 


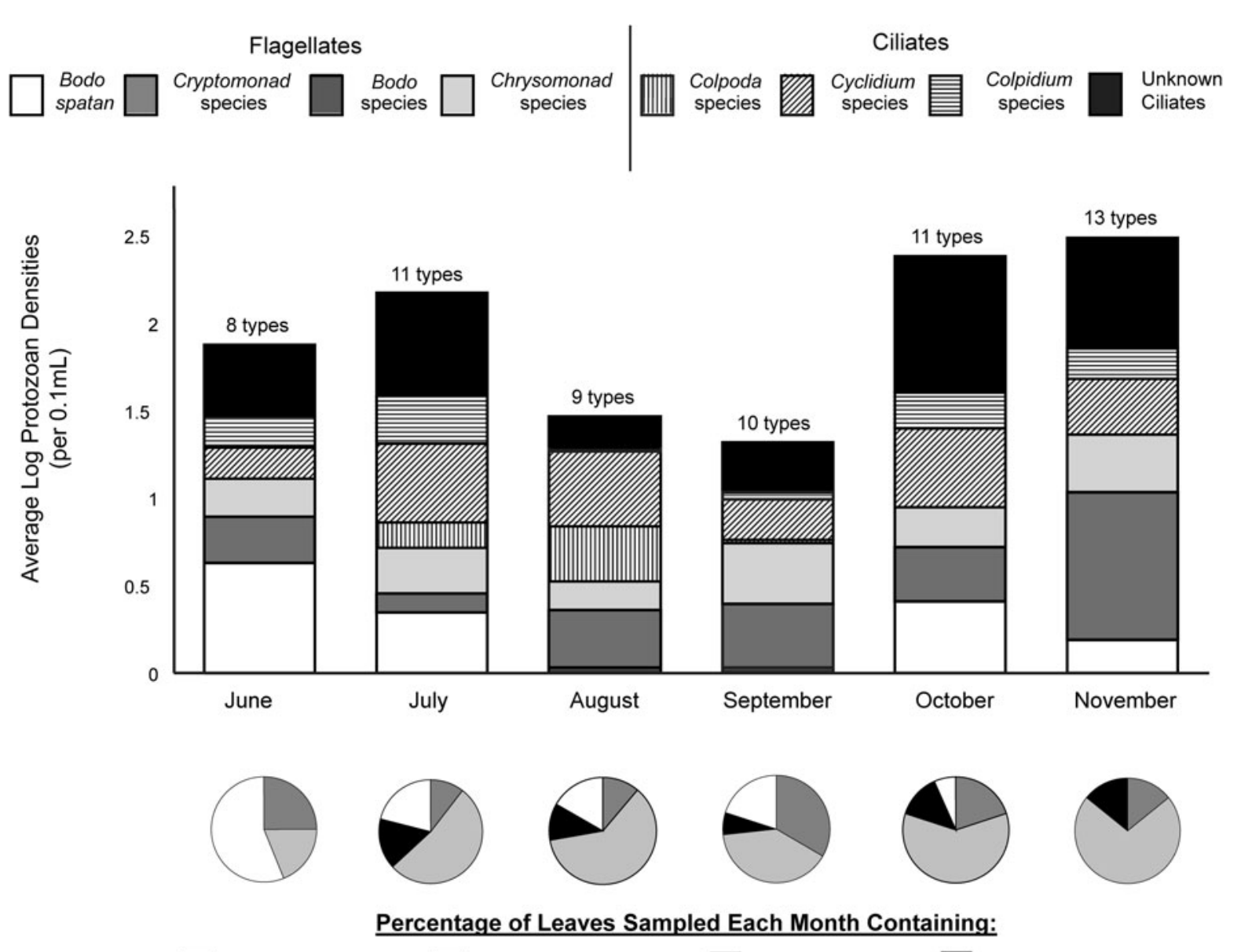

Fig. 4 Composition of $\sim 20$ protozoan communities sampled monthly from June to November in 2007. Each bar on the graph represents the average log protozoan densities per month. Each stacked bar represents the density of a specific protozoan species. Densities and richness were obtained by counting protozoans in $0.1 \mathrm{ml}$ aliquots. The upper black bars in each month represent the densities and species richness of ciliate

to compare the similarity in the successional pattern between a larger subset of bacteria than that of just the culturable bacteria, which are only $1 \%$ of the bacterial diversity. When cloning is used instead of highthroughput sequencing (e.g., Koopman et al. 2010; Koopman and Carstens 2011), a much smaller sampling of diversity occurs. Therefore, this study is not claiming to capture the entire bacterial diversity in this system. Instead, by using cloning techniques, a larger subset of the diversity (both culturable and unculturable) is provided than what is found with agar plate counts. This allows for a comparison between the two methods to be made in order to understand whether the protozoans with unknown competitive ability. The remaining bars represent the protozoan species with known competitive ability (Kneitel 2002). The pie charts represent the percentage of leaves sampled each months that contained no protozoans, flagellates only, ciliates only or both flagellates and ciliates together

use of agar plate counts is adequate for acquiring accurate measures of the relative richness and abundance of the bacteria in this system. The cloning method also allows for species identification, which is essential knowledge lacking in the Sarracenia system.

The MDS plots for culturable and OTU bacteria revealed that when looking at the beginning (June) and end (November) of the season time points, there is a large seasonal difference in the bacterial community (abundances of culturable bacteria morphotypes in 2007, Fig. 5a, ANOSIM $=0.677, p$ value $=0.001$; and 2008 OTU data, Fig. 5b; $\operatorname{ANOSIM}=1$, $p$ value $=0.002$ ). In both cases, bacterial communities 
Table 1 The averaged log densities and the average species richness of culturable bacteria and protozoans in the 20 communities sampled through one growing season

\begin{tabular}{|c|c|c|c|c|c|c|c|c|}
\hline \multirow[t]{2}{*}{ Month } & \multicolumn{2}{|c|}{$\begin{array}{l}\text { Avg. } \log \text { density of culturable } \\
\text { bacteria }\end{array}$} & \multicolumn{2}{|c|}{$\begin{array}{l}\text { Avg. culturable bacteria } \\
\text { richness }\end{array}$} & \multicolumn{2}{|c|}{$\begin{array}{l}\text { Avg. } \log \text { density of } \\
\text { protozoans }\end{array}$} & \multicolumn{2}{|c|}{$\begin{array}{l}\text { Avg. protozoan } \\
\text { richness }\end{array}$} \\
\hline & & $\mathrm{SE}+/-$ & & $\mathrm{SE}+\mathrm{I}-$ & & $\mathrm{SE}+/-$ & & $\mathrm{SE}+/-$ \\
\hline June & 10.86 & 0.282 & 3 & 0.072 & 1.19 & 0.132 & 0.667 & 0.065 \\
\hline July & 6.40 & 0.263 & 2.26 & 0.089 & 1.91 & 0.091 & 1.74 & 0.093 \\
\hline August & 4.49 & 0.121 & 3.55 & 0.061 & 1.56 & 0.126 & 1.61 & 0.089 \\
\hline Sept. & 4.21 & 0.111 & 2.69 & 0.067 & 1.56 & 0.121 & 1.67 & 0.112 \\
\hline October & 4.54 & 0.126 & 3.26 & 0.073 & 2.66 & 0.132 & 2.27 & 0.102 \\
\hline Nov. & 4.23 & 0.126 & 3.64 & 0.091 & 2.49 & 0.124 & 2.21 & 0.0894 \\
\hline
\end{tabular}

Average log culturable bacteria densities (per $0.1 \mathrm{ml}$ ) were high in June and decrease throughout the growing season. Variation between samples (standard error) also decreased throughout the growing season. Protozoans showed the opposite pattern as the culturable bacteria. Protozoan average log densities (per $0.1 \mathrm{ml}$ ) increased through time. Culturable bacteria species richness remained relatively constant throughout the growing season; however, protozoan species richness increased through time

\section{$\triangle$ Beginning of Season (June)}

(a) Culturable Bacteria Abundances

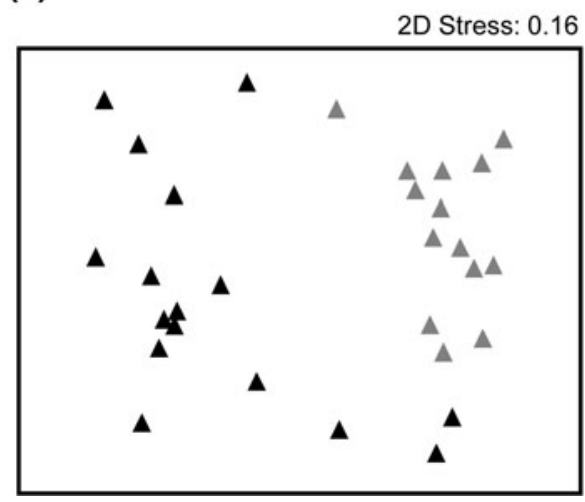

Fig. 5 Non-metric multi-dimensional scaling (MDS) plots comparing bacteria similarity between communities sampled at the beginning (June, black triangles) and end (November, gray triangles) of the season for a abundances of individual culturable bacteria morphotypes sampled in 2007 and b abundances of individual bacterial OTUs that were sampled in 2008. Data used for MDS plots and ANOSIMS were square-roottransformed Bray-Curtis similarities. Each symbol represents

sampled at the beginning of the season were more similar to each other than to any of the end of the season communities (Fig. 5a, b).

The types of bacterial species found in the communities (presence/absence data) also depended on the sampling time period, and this pattern was seen both when culturable bacteria morphotypes were determined in 2007 and when bacterial OTUs were used in 2008. Communities sampled at the beginning of the season

\section{End of Season (November)}

\section{(b) Bacterial OTU Abundances}

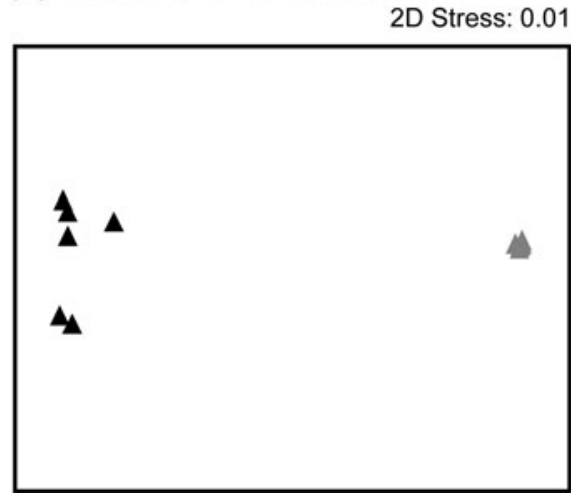

the bacterial community in one leaf. analysis of similarity (ANOSIM) global R is 0.667 ( $p$ value $=0.001$ ) for culturable bacteria abundances $(\mathbf{a})$ and 1 ( $p$ value $=0.002)$ for similarity based on abundances of individual OTUs (b). The bacterial communities based on both culturable bacteria and OTU abundances were significantly different between the beginning of the season and the end of the season

had greater variation between samples, but converged by the end of the season such that each community contained a very similar subset of species from the total species pool, but was different in the identity of those found at the beginning of the season (Figure S3a, b). This pattern was more evident when OTU data were used $($ ANOSIM $=0.999, p$ value $=0.002)$ than when culturable bacteria morphotypes were used (ANO$\mathrm{SIM}=0.352, p$ value $=0.001)$. 
In the OTU study, the identification of the dominant bacteria present at the beginning and end of the season was as follows. When the abundances of bacterial types from all communities sampled at the beginning of the season were pooled together, the most abundant class of bacteria was Gammaproteobacteria (38\% of the all sequences in June samples). At the end of the season, the dominant class of bacteria switched to Betaproteobacteria and Sphingobacteria (37 and $38 \%$ of the total sequences in November samples, respectively). When comparing the variation in the abundance of the dominant bacterial class between samples, at the beginning of the season, Gammaproteobacteria was found on average to be $38 \%$ of the sequences within a sample, but this number deviated by $28 \%$ between samples. At the end of the season, the two most dominant bacterial classes were found to be on average 35 and $36 \%$ of the sequences within a sample and were less variable in abundance between samples than the dominant bacterial class at the beginning of the season (standard deviation of 14 and $16 \%$, respectively). The number of classes also shifted from the beginning to the end of the season, with 6 classes of bacteria present at the beginning of the season and 10 present at the end of the season.

\section{Discussion}

By following multiple aquatic $S$. purpurea communities within the same habitat throughout a growing season, I found that community composition shifted through time for both the bottom and intermediate trophic level and that the presence of resources and the top predator greatly changed during succession. However, contrary to the idea proposed by Clements (1916, 1936), competitively superior species were found to establish in newly forming communities and coexist with less competitive species throughout the growing season. This finding suggests that for this system there is no requirement for early successional species to first modify the environment for the competitively dominant species to successfully establish. Interestingly, the diversity of ciliates in the intermediate trophic level was found to increase through time, suggesting that the community acquires more species through time instead of replacing species. These same results, which are from Sarracenia communities located in the mid-range of the plant's distribution, were also found in the $S$. purpurea community in the southern part of the range (Miller and terHorst 2012), showing that not only is species identity of this community similar throughout the geographic range (Buckley et al. 2003, 2010), but also community dynamics during succession.

The importance of top-down predator and bottom-up resource control in driving patterns of succession was not easily determined in this study, and other intrinsic and extrinsic factors (e.g., propagule pressure, disturbance, size of regional pool, temperature, $\mathrm{pH}$, disturbance) may also affect the successional trajectory of this system, but were not tested in this study. According to the results, the similarity of individual communities within a month appears to be more affected at the intermediate trophic level than at the bottom trophic level, with communities containing a top predator more similar to each other than communities not containing a top predator and with community similarity unaffected by resource input. This top predatory effect matches results from an experiment conducted in ponds by Chase et al. (2009).

This pattern flips when community composition is compared across months. The lack of ant input from August to November created low-resource habitats, affecting the abundance and species identity of the bacteria. As a result, bacterial communities were more similar within a month than between months, and the months containing the largest ant input (June and July) were more similar to each other than to the months containing no or very little ant input.

When OTU data were used in 2008, communities at the beginning of the season were more similar to each other than to communities at the end of the season, both when presence/absence and abundance data were used. A similar result was found when 454 sequencing was using to identify the seasonal change in bacterial composition inside the leaves of the co-gener, S. alata (Koopman et al. 2010). A similar, but weaker, pattern was also found for similarities based on abundance data for the culturable bacteria collected from the 20 pitchers in 2007. This result suggests that the sampling method that used only a small percentage of bacteria (the culturable bacteria) provides a similar pattern as to when a larger subset of bacteria is obtained through 16S rRNA cloning for assessing successional patterns.

In terrestrial systems, research has traditionally followed the belief that succession is either deterministic (Clements 1916) or stochastic (Gleason 1927), 
with very little matching data existing in aquatic food webs. The research presented here takes a step toward understanding the process of succession in aquatic systems. I found that, for the model Sarracenia system, both deterministic and stochastic properties may be acting simultaneously, but at different scales. If communities are examined within a month, high variation occurs which may be explained, in part, by top predator forces. However, when communities are examined through time, communities at the beginning and end of succession differ in composition, with communities at the beginning of the season more similar to each other in composition than communities at the end of the month. This result would suggest the deterministic succession is occurring in some aspects, but not in others (early settlers are not out-competed by the more competitive later settlers; Clements 1916, 1936). More research needs to be done to understand what mechanisms drive the patterns of community succession in both the $S$. purpurea system and other aquatic systems, microbial and non-microbial, in order for generalizations about predictable patterns in aquatic community succession to be made.

Acknowledgments I would especially like to thank Dianna Padilla, Dan Dykhuizen, Jessica Gurevitch, Shahid Naeem, Olivier Broennimann and three anonymous reviewers for their edits, useful comments and insight throughout this project. I am grateful to the Stony Brook University undergraduates, Maria Aguilar and Miriam Habiel, for their field assistance and to collaborator Denise Akob for her help with producing clone libraries. This project was funded by the Stony Brook University Slobodkin Award and by grant number NIH GM060731 with Dan Dykhuizen as the PI. This is contribution 1217 from the Department of Ecology and Evolution at Stony Brook University.

\section{References}

Berlow EL (1997) From canalization to contingency: historical effects in a successional rocky intertidal community. Ecol Monogr 67:435-460

Bray JR, Curtis JT (1957) An ordination of the upland forest communities of southern Wisconsin. Ecol Monogr 27:325-349

Buckley HL, Miller TE, Ellison AM, Gotelli NJ (2003) Reverse latitudinal trends in species richness of pitcher-plant food webs. Ecol Lett 6:825-829

Buckley HL, Miller TE, Ellison AM, Gotelli NJ (2010) Local- to continental-scale variation in the richness and composition of an aquatic food web. Global Ecol Biogeogr 19:711-723
Chase JM, Biro EG, Ryberg WA, Smith KG (2009) Predators temper the relative importance of stochastic processes in the assembly of prey metacommunities. Ecol Lett 12:1210-1218

Clarke KR, Gorley RN (2006) PRIMER v6: user manual/tutorial. Plymouth, PRIMER-E

Clements FE (1916) Plant succession: an analysis of the development of vegetation. Carnegie Institution of Washington, Washington, p 512

Clements FE (1936) Nature and structure of the climax. J Ecol 24:252-284

Connell JH, Slatyer RO (1977) Mechanisms of succession in natural communities and their role in community stability and organizations. Am Nat 11:1119-1144

DeSantis TZ, Hugenholtz P, Keller K, Brodie EL, Larsen N, Piceno YM, Phan R, Andersen GL (2006) NAST: a multiple sequence alignment server for comparative analysis of 16S rRNA genes. Nucleic Acids Res 34:W394-W399

Fish D, Hall DW (1978) Succession and stratification of aquatic insects inhabiting the leaves of the insectivorous pitcher plant, Sarracenia purpurea. Am Midl Nat 99:172-183

Gleason HA (1917) The structure and development of the plant association. Bull Torrey Bot Club 43:463-481

Gleason HA (1927) Further views on the succession-concept. Ecology 8:299-326

Gotelli NJ, Ellison AM (2006) Food-web models predict species abundance in response to habitat change. PLoS Biol 44:e324

Gray SM (2011) Community assembly dynamics and consequences of invasion: tests with the Sarracenia purpurea model system. PhD diss. Stony Brook University, Stony Brook, NY

Gray SM, Miller TE, Mouquet N, Daufresne T (2006) Nutrient limitation in Sarracenia purpurea microcosms. Hydrobiologia 573:173-181

Heard SB (1994) Pitcher-plant midges and mosquitoes: a processing chain commensalism. Ecology 75:1647-1660

Hutchinson GE (1961) The paradox of the plankton. Am Nat 95:137-145

Johnson JL (1994) Similarity analysis of rRNAs. In: Gerhardt PE, Wood WA, Krieg NR (eds) Methods for general and molecular bacteriology. Am Soc Microbiol, Washington, DC, pp 683-700

Kneitel JM (2002) Species diversity and trade-offs in pitcher plant (Sarracenia purpurea) inquiline communities. $\mathrm{PhD}$ diss. Florida State University, Tallahassee, FL

Kneitel JM, Miller TE (2002) The effects of resource and toppredator addition to the inquiline community of the pitcher plant Sarracenia purpurea. Ecology 83:680-688

Koopman M, Carstens BC (2011) The microbial phyllogeography of the carnivorous plant Sarracenia alata. Microb Ecol 6:750-758

Koopman M, Fuselier D, Hird S, Carstens BC (2010) The carnivorous pale pitcher plant harbors diverse, distinct and temporally dependent bacterial communities. Appl Environ Microbiol 76:1851-1860

Miller TE, terHorst CP (2012) Testing successional hypotheses of stability, heterogeneity, and diversity in pitcher-plant inquilines communities. Oecologia 170:243-251

Odum EP (1969) The strategy of ecosystem development. Science $164: 262-270$ 
Paine RT (1966) Food web complexity and species diversity. Am Nat 100:65-75

Peterson CN, Day S, Wolfe BE, Ellison AM, Kolter R, Pringle A (2008) A keystone predator controls bacterial diversity in the pitcher plant (Sarracenia purpurea) microecosystem. Environ Microbiol 10:2257-2266
Wilson KH, Blitchington RB, Greene RC (1990) Amplification of bacterial 16S ribosomal DNA with polymerase chain reaction. J Clin Microbiol 28:1942-1946 